\title{
Is There a Place for Esogastric Cancer Surgery in Cirrhotic Patients?
}

\author{
Christophe Mariette, MD, $\mathrm{PhD}$ \\ Department of Digestive and Oncological Surgery, University Hospital C. Huriez - Centre Hospitalier Régional Universitaire \\ and University of Lille II, Place de Verdun, 59037, Lille cedex, France
}

It is well established that surgery, especially gastrointestinal cancer surgery, in nonbleeding cirrhotic patients carries a high risk of mortality and morbidity. Esophagogastrectomy for carcinoma in cirrhotic patients has been mentioned only occasionally in the literature. Our aim was to review literature results in esophageal and gastric cancer surgery, to identify cirrhotic patients who will benefit from surgery, and to give to surgeons technical specificities of such surgery.

\section{ESOPHAGEAL CANCER}

The surgical management of esophageal cancer in cirrhotic patients is associated with significant morbidity and mortality, with rates of $83-87 \%$ and $17-30 \%$, respectively. ${ }^{1-5}$ These figures are comparable to the morbidity and mortality rates in noncirrhotic patients, which are of the order of $30-40 \%$ and below $5 \%$, respectively. ${ }^{6,7}$

The most common causes of morbidity and mortality following surgical treatment of esophageal cancer are pulmonary complications and fistulas. These complications are not significantly more frequent in cirrhotic patients. ${ }^{3,4}$ Pulmonary complications do not result in increased mortality different from that observed for other infectious complications (fistulas, sepsis) which are responsible for postoper-

Published online: January 3, 2008.

Address correspondence and reprint requests to: Christophe Mariette, MD, PhD; E-mail: c-mariette@chru-lille.fr

Published by Springer Science+Business Media, LLC @ 2007 The Society of Surgical Oncology, Inc. ative demise in about two-thirds of patients. ${ }^{3,4}$ The most common complication in cirrhotic patients following esophageal surgery is ascitic effusion, which is the cause of death in about one-third of patients. ${ }^{3}$ This ascites is associated with the interruption of the esophageal and periesophageal vascular collaterals and with extensive lymph node dissection. Heavy perioperative blood loss increases the mortality. ${ }^{4}$ Postoperative hepatic insufficiency is fatal in just less than one patient in two. Specific and almost inevitably fatal postoperative complications are hepatorenal syndrome and portal thrombosis. ${ }^{3}$

The preoperative factors predictive of postoperative mortality in cirrhotic patients proposed for esophagectomy are (1) the degree of hepatic insufficiency reflected by the Child score, a Child score of $\mathrm{B}$ or $\mathrm{C}$ being associated with unacceptable postoperative mortality, (2) a prothrombin value $\leq 60 \%$, and (3) acute alcoholic hepatitis ${ }^{1-3}$ and weight loss exceeding $15 \%$ of body weight. ${ }^{4}$ The approach (with or without thoracotomy or thoracic or cervical anastomosis) has not been shown to influence postoperative mortality. ${ }^{3}$

In terms of survival, the prognosis of cirrhotic patients appears more severe than for noncirrhotic patients at the same stage $(21 \%$ vs $42 \% 3$-year survival, respectively, $P=.051) .{ }^{4}$ Nevertheless, after excluding postoperative deaths, there does not appear to be any prognostic difference between cirrhotic and noncirrhotic patients, ${ }^{4,5}$ in particular regarding mortality beyond the postoperative period in relation to a complication of cirrhosis. The suggested explanations are suppression of the collaterals secondary to esophagectomy and alcoholic withdrawal secondary to the relative postesophagectomy loss of appetite. ${ }^{4,5}$ 


\section{GASTRIC CANCER}

Gastric surgery excluding bleeding in cirrhotic patients is associated with slightly increased morbidity and mortality, with mean rates of $40 \%$ and $10 \%$, respectively, for gastric cancer. ${ }^{8,9}$ These figures are comparable to the morbidity and mortality rates in noncirrhotic patients, which are of the order of $20 \%$ and below $3 \%$, respectively. ${ }^{10}$

In cirrhotic patients operated on for gastric cancer, the most common postoperative complications are ascites (14\%), wound infections (11\%), and hepatic encephalopathy. The hemorrhagic and infectious complications are slightly higher with rates of about $4.3 \%$ and $9 \%$, respectively. The risk of anatomotic leakage does not appear to be increased. ${ }^{11}$

The preoperative factors predictive of postoperative mortality in cirrhotic patients proposed for gastrectomy are (1) the degree of hepatic insufficiency reflected by the Child score, a Child score of B or C being associated with unacceptable postoperative mortality, (2) preoperative liver function test abnormalities, especially an aspartate transaminase (ASAT) rate $>40 \mathrm{UI} / \mathrm{L},(3)$ a preoperative transfusion indicating a hemorrhagic event, ${ }^{12}$ (4) an aspiration drain, ${ }^{11,13}$ and (5) and extensive dissection especially of the hepatoduodenal ligament, promoting the onset of considerable postoperative ascites..$^{9,11,14}$ The extent of the gastrectomy does not seem to influence the surgical sequelae. ${ }^{11}$

With regard to survival, the prognosis of cirrhotic patients appears to be worse than that for noncirrhotic patients at the same stage. In contrast to esophageal cancer, after excluding postoperative mortality, the main causes of decease are related to the development of the cirrhosis such as the hepatic insufficiency, hemorrhagic complications, and hepatic cancer. ${ }^{9,15}$

\section{CONCLUSION}

Because cirrhotic patients with esogastric cancer have the same chance of cure as do noncirrhotic patients when postoperative complications are managed well with low mortality rate, the mere presence of cirrhosis should not be considered a contraindication for curative surgery. Esophagectomy and gastrectomy for cancer in cirrhotic patients should only be considered for very carefully selected patients, even if the selection appears to have to be less strict for gastric cancer, i.e., Child A patient, normal preoperative liver function tests, and no previous history of edematoascitic decompensation. The specific surgical aspects are (1) perfect hemostasis, (2) avoidance of postoperative drainage for gastric cancer whereas it seems to be recommended for esophageal cancer, (3) prevention of infections, (4) water and sodium restriction and compensation of electrolyte losses, and (5) nutritional support. For locally advanced squamous cell carcinoma of the esophagus, this potentially morbid surgery is to be balanced against definitive chemoradiation that allowed 2-year survival rates similar to chemoradiation followed by surgery. ${ }^{16}$

Whether for cancer of the stomach or esophagus, the best candidates for surgery are patients without clinical and biological symptoms in whom the cirrhosis is discovered by chance during surgery.

\section{REFERENCES}

1. Garrison RN, Cryer HM, Howard DA, Polk HC Jr. Clarification of risk factors for abdominal operations in patients with hepatic cirrhosis. Ann Surg 1984; 199:648-55.

2. Doberneck RC, Sterling WA Jr, Allison DC. Morbidity and mortality after operation in nonbleeding cirrhotic patients. $\mathrm{Am}$ J Surg 1983; 146:306-9.

3. Fekete F, Belghiti J, Cherqui D, et al. Results of esophagogastrectomy for carcinoma in cirrhotic patients. A series of 23 consecutive patients. Ann Surg 1987; 206:74-8.

4. Tachibana M, Kotoh T, Kinugasa S, et al. Esophageal cancer with cirrhosis of the liver: results of esophagectomy in 18 consecutive patients. Ann Surg Oncol 2000; 7:758-63.

5. Lu MS, Liu YH, Wu YC, Kao CL, Liu HP, Hsieh MJ. Is it safe to perform esophagectomy in esophageal cancer patients combined with liver cirrhosis?. Interact Cardiovasc Thorac Surg 2005; 4:423-5.

6. Mariette C, Piessen G, Lamblin A, Mirabel X, Adenis A, Triboulet JP. Impact of preoperative radiochemotherapy on postoperative course and survival in patients with locally advanced squamous cell oesophageal carcinoma. Br J Surg 2006; 93:1077-83.

7. Mariette C, Piessen G, Balon JM, Van Seuningen I, Triboulet JP. Surgery alone in the curative treatment of localised oesophageal carcinoma. Eur J Surg Oncol 2004; 30:869-76.

8. Jang HJ, Kim JH, Song HH, et al. Clinical outcomes of patients with liver cirrhosis who underwent curative surgery for gastric cancer: a retrospective multi-center study. Dig Dis Sci 2007; Jun 28 [E-pub].

9. Isozaki H, Okajima K, Ichinona T, et al. Surgery for gastric cancer in patients with cirrhosis. Surg Today 1997; 27:17-21.

10. Sano T, Sasako M, Yamamoto S, et al. Gastric cancer surgery: morbidity and mortality results from a prospective randomized controlled trial comparing D2 and extended para-aortic lymphadenectomy - Japan Clinical Oncology Group study 9501. J Clin Oncol 2004; 22:2767-73.

11. Lee JH, Kim J, Cheong JH, et al. Gastric cancer surgery in cirrhotic patients: result of gastrectomy with D2 lymph node dissection. World J Gastroenterol 2005; 11:4623-7.

12. Karl RC, Schreiber R, Boulware D, et al. Factors affecting morbidity, mortality, and survival in patients undergoing Ivor Lewis esophagogastrectomy. Ann Surg 2000; 231:635-43.

13. Liu CL, Fan ST, Lo CM, et al. Abdominal drainage after hepatic resection is contraindicated in patients with chronic liver diseases. Ann Surg 2004; 239:194-201. 
14. Takeda J, Toyonaga A, Koufuji K, et al. Surgical management of gastric cancer patients with liver cirrhosis. Kurume Med J 1994; 41:205-13.

15. Takeda J, Hashimoto K, Tanaka T, et al. Review of operative indication and prognosis in gastric cancer with hepatic cirrhosis. Hepatogastroenterology. 1992; 39:433-6.
16. Mariette C, Piessen G, Triboulet JP. Therapeutic strategies in oesophageal carcinoma: role of surgery and other modalities. Lancet Oncol 2007; 8:545-53. 